\title{
A Study to Assess Effect of Information Booklet on Knowledge Regarding Side Effect Management in the Patients of Head and Neck Cancer Undergoing External Radiation Therapy in Selected Hospital
}

\author{
Ujjwala Murkute $^{1}$, Shaikh Nida Nausheen ${ }^{2}$ \\ ${ }^{1}$ M. Sc Nursing (Medical Surgical Nursing), Associate Professor, Sadhu Vaswani College of Nursing, Pune, \\ Maharashtra, India \\ ${ }^{2}$ M. Sc Nursing (Medical Surgical Nursing), Lecturer, MGM Mother Teresa College of Nursing, Aurangabad, \\ Maharashtra, India \\ Corresponding Author: Ujjwala Murkute
}

\begin{abstract}
Objectives: - To evaluate the effectiveness of informational booklet regarding side effects management in patient undergoing external radiation therapy.

Methods: Quasi experimental pre test post test design was used in the study at radiation therapy department in cancer institute. 35 patients of head and neck cancer undergoing external radiation therapy received information booklet regarding side effect management of external radiation therapy in their first week of treatment. Knowledge regarding side effect management of external radiation therapy was assessed one week later.

Results: - In pre test there was $51.1 \%$ patients with poor knowledge, $48.6 \%$ had average knowledge and no one had good knowledge whereas the post test scores are increased by $85.7 \%$ with good knowledge, $14.3 \%$ had average knowledge and no one had poor knowledge. There is significant difference of knowledge score between pre and post test as $\mathrm{P}<0.0001$ i.e. knowledge score significantly increased after administering information booklet. Sociodemographic variable age, gender, educational status, family income \& type of treatment were found to have no association with knowledge score regarding management of side effects.

Conclusion: - Radiation therapy is one of the important treatments for cancer but can also cause side effects. These Side effects of radiation therapy are very common and can affect the quality of life of the cancer patients. There was significant impact of information booklet on knowledge regarding side effects management of radiation therapy among head and neck cancer patients. Hence using information booklet as an education material can be helpful in teaching patients self care behaviours, prevent the side effects of radiation therapy and improve the quality of life.
\end{abstract}

Key Words: - Information booklet, external radiation therapy, head and neck cancer, side effect management

\section{INTRODUCTION}

Cancers in the developed countries are the second most common cause of mortality following heart diseases. Cancer is a universal disease that affects people without regard to race, gender, socioeconomic status, or culture. Head and neck cancer is the fifth most common cancer worldwide with an estimated annual global incidence of more than 533,000 cases. $^{[1]}$ More than half of patients with cancer receive a form of radiation therapy at some point during treatment. After surgery, it is the most effective curative treatment for cancer. The value of the radiotherapy lies mainly in its local application, whereby 
defined areas, which might otherwise inoperable, can be treated successfully. Radiation causes damage to both normal and malignant cells, but damage is confined to the area of treatment delivery. ${ }^{[2]}$

Radiotherapy is a treatment modality largely used for head and neck malignancies and although presents a significant increase in cure rates, it is still associated with several and complex oral complications. This therapy presents many challenges primarily because the head and neck region has many critical structures that can be damaged by tumor or treatment. Damage to these tissues by tumor or therapy can result in significant structural, cosmetic and functional deficits that negatively impact on quality of life. ${ }^{[2],[3]}$

Radiation effects may be categorized as acute (during treatment to 6 months), sub-acute (after 6 months), and chronic (with variable time to expression). The effects are seen sooner in cell lines with a high mitotic index (the skin, mucous membranes, and hair follicles) and later in cell lines that divide more slowly (the vascular system and muscle. Side effects from radiotherapy vary, but are mainly localized to the area being treated. Adverse effects of treatment can be very debilitating and can have a substantial impact on quality of life.

Radiation to head and neck can cause a whole range of problems to skin, salivary glands, mucosa and bone. Side effects caused by radiotherapy are usually related to area which is being treated. Patients receiving head and neck radiation show mild skin reaction $80-90 \%$, erythema and severe reactions such as moist desquamation $10-15 \%$ and mucositis $60 \%$, patient often describe dry mouth, eating difficulties related to swallowing or taste changes and pain. There are however, a number of generalized effects, which are not related to a particular area but are extremely common such as extreme fatigue (75\%) gastrointestinal effects (89-100\%) in which upper abdominal irritation $50-80 \%$, urinary symptoms $23-80 \%$, alopecia. ${ }^{[4]}$
Nurses are in a strategic position to lead efforts at changing attitudes and behaviours about cancer. Misapprehensions about radiotherapy may be due to the lack of information prior to the planning session. Furthermore, it is clearly an important nursing goal to implement educational interventions that will assist individuals to understand, reduce or eliminate their risk of cancer development.

\section{Need of the study}

Guleser GN, et al, (2012) mentioned in the article 'The experience of symptoms and information needs of cancer patients undergoing radiotherapy' that most patients $(80.9 \%)$ experienced radiation therapy side effects- fatigue, nausea, vomiting and loss of appetite were most frequent. More than half of patients had not received information about radiation therapy. However, $(83.2 \%)$ who had problems during the treatment wanted to have information. Overall, the results indicates that most patient require information about their treatment and also experienced a variety of symptoms. ${ }^{[5]}$ It is recognized that providing information can affect perceptions of radiotherapy side effects and reduce anxiety, clearly radiotherapy information require more effort. Video and photographs of the radiotherapy centre and machines as well as information as to sounds that might be heard during the course of treatment can help to reduce patient's initial anxiety. ${ }^{[6]}$ Rutten LJ, et.al (2005) conducted a study on 'Information needs and sources of the information among cancer patients: a systematic review of research' states that most frequent information need was treatment related $(38.1 \%)$. The most frequent information source was health professional. The study suggested -future research can be done on examining the cancer patient; information needs and sources throughout their cancer journey. ${ }^{[7]}$ Hagopian GA, conducted the study on 'the informational audiotape on knowledge and self-care behaviors of patients undergoing radiation therapy' states that Patients in the 
experimental group were more knowledgeable about radiation therapy and its side effects, used more self-care measures, and practiced more helpful selfcare behaviors than control group subjects treated successfully. ${ }^{[8]}$

Skalla KA, et al (2004), conducted study on patient's need for information about cancer therapy' with the objectives of to obtain detailed information about the preferences of patients with cancer and their need for information about side effects of cancer treatment to design an interactive multimedia educational program. They found that although most patients wanted as much information as possible so they would be prepared for whatever happened, some patients preferred to avoid information about possible side effects. Several obstacles related to information were reported, including access to providers, communication difficulties with providers, informational overload, and problems with retention. The study suggested that new approaches to patient education that will meet the needs of patients as well as clinicians and educators need to be developed ${ }^{[9]}$

Jeff Dunn, et al (2004) conducted a study on educating patient education materials about radiation therapy, mentioned in the article that $90 \%$ of patients in the intervention group reported that some or all of the information in the video was new to them. Future research in this area may need to consider alternative paradigms for evaluating the helpfulness of such materials. ${ }^{[10]}$

Based on the review of literature, personal experience of the investigator in the oncology unit, it was found that there is need for to provide the patients education that is understandable and helpful to improve coping and adjusting with the bodily changes there are very few studies dealing with effectiveness of information booklet on side effect management in the patients of head and neck cancer undergoing radiation therapy, thus the investigator would like to explore on the effects of planned information booklet -on management of selected side effects of Radiation Therapy and make significant contribution to the field of radiation oncology nursing in achieving a better quality of life for patients receiving Therapy.

\section{Conceptual Framework}

The conceptual framework for the study is based on Dorothea Orem self care deficit nursing theory. This theory focuses on the patient's deliberate actions to meet their own and dependant other's therapeutic self care demands and nurse's deliberate actions to implement nursing systems designed to assist individual and multiperson units who have limitations in their abilities. In this study therapeutic self care demand comprises knowledge about side effects of head and neck radiation therapy and its management, Medications and referral services, psychological needsanxiety, depression \& Ineffective coping with bodily changes with increasing side effects of radiation therapy. Self care agency comprises- Hydration, Personal hygiene, Protection of skin, Diet maintenance \& Life style modification. Nursing agency comprises developed capabilities of persons educated as nurses that empower them to represent themselves as nurses that empower them to represent themselves as nurses and within the frame of legitimate interpersonal relationship to act, to know, and to help persons in such relationships to meet their therapeutic self care demands and to regulate the development or exercise of their self care agency. Conditioning factor in this study are age, gender, development state, health state, living pattern, socio cultural factors, availability of resources and external environmental factors. ${ }^{[11]}$ [figure 1] 


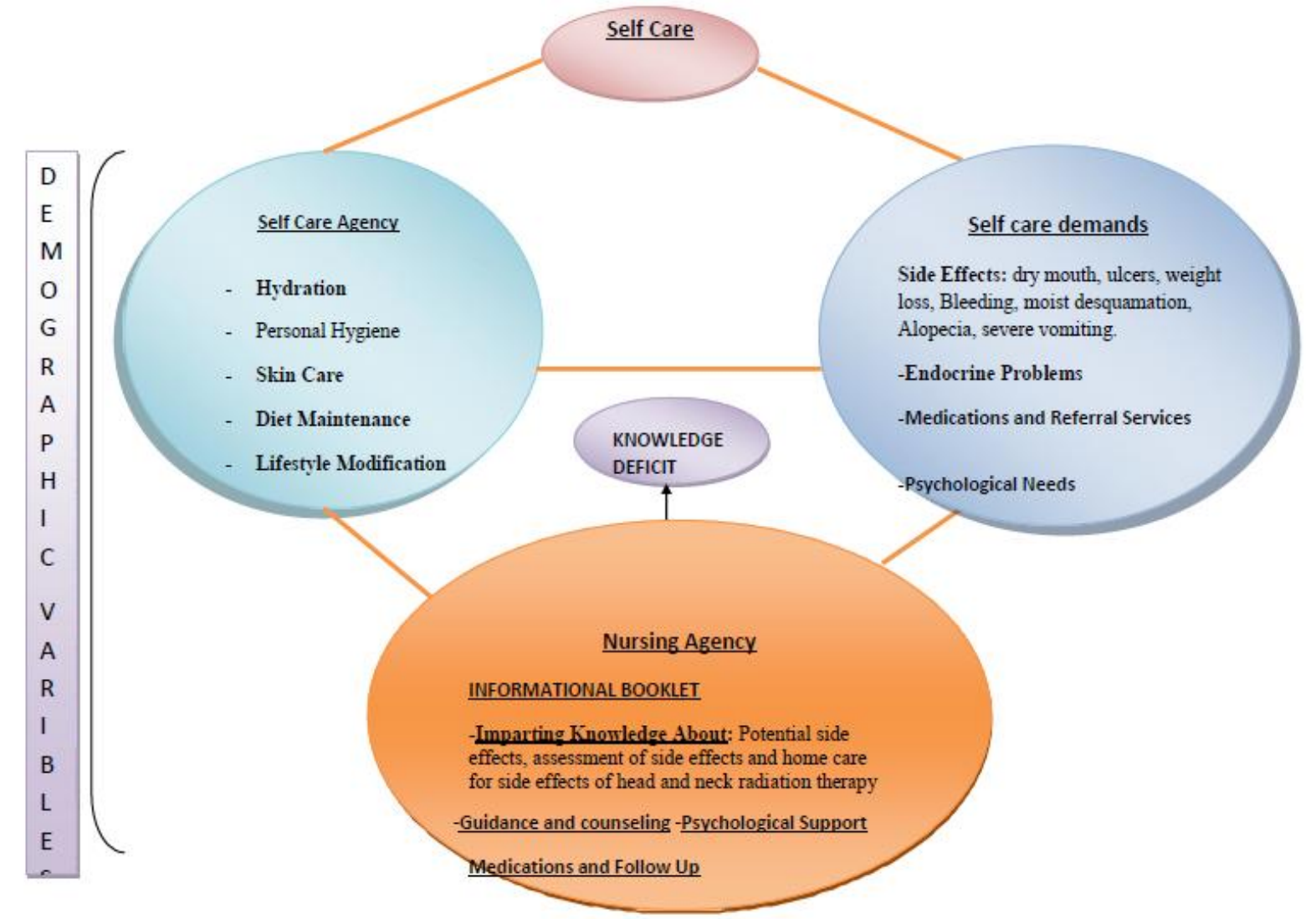

Fig.1 Original: Conceptual Framework based on Orem's Self Care Deficit theory

\section{METHODS}

Patients undergoing external radiation therapy for head and neck cancers were included in the study who were fulfilling the following inclusion criteria

1. Patients who are willing to participate in the study.

2. Patients receiving external radiation therapy for head and neck tumors.

3. Patients in first week of external radiation therapy.

Exclusion criteria of the study included patients who were/had

1. In-patient

2. visual impairment

3. known cognitive impairment

4. known psychiatric illness

5. previous history of radiation therapy

To select the sample needed for the study, the investigator approached the proper authorities for obtaining the necessary permission and cooperation. The nature of the study was briefly explained and it was ensured by the investigator that the normal routine of the department won't be disturbed. Demographic data of the patient receiving radiation therapy for head and neck cancer were collected then by using the self structured questionnaire. Keeping in view the objectives of the study, the research selected for the study was on group pre test post test design (O1 X O2).

\section{Interventions: Information booklet on side effect management of radiation therapy}

The booklet aimed to increase the knowledge and comprehension of cancer patients regarding management of side effects of radiation therapy.

The steps adopted in the development of booklet were: Preparation of the first draft on the booklet, Content validation of the booklet, Preparation of the final draft of the booklet \& Production of booklet. 
The first draft of the booklet was prepared based on research literature and non-research literature on management of side effects of head and neck radiation therapy. Literature was also reviewed on the development of booklet. The factors considering while developing the booklet were independent learning, self pacing, convenience in reading and size. The booklet was developed in English and validated .Self pacing would give an opportunity to both fast and slow learner. The language of booklet was kept as simple as possible. The booklet was designed using an easy print text with illustrations, and was given a title 'Side effect management of radiation therapy for head and neck cancer' The areas covered in booklet were:

1. Concept of radiation therapy.

2. Side effects of head and neck radiation therapy.

3. Management of side effect of head and neck radiation therapy.

Pre test was conducted before giving information booklet to selected patients. Apart from giving the information booklet, the nurse also encouraged the two way communication among patients and herself. she also followed up with them for the period of one week. patients were motivated to read the information booklet and give feedback if any in coming follow up sessions. Depending on patient's educational background and knowledge level, encouragement and reinforcement and support were provided. Post test was conducted after 5 days of giving information booklet.

\section{Instrument}

There were two sections made for data collection:

Section I:- consisted of 5 items on socio demographic background i.e. age, gender, educational status, family income \& type of treatment

Section II compromised of 26 items with maximum score of 26 categorized under three areas as follows: Concept of radiation therapy, Side effects of head and neck radiation therapy \& Management of side effect of head and neck radiation therapy.

Structured knowledge questionnaire was prepared for assessing the knowledge regarding side effects management of head and neck radiation based on the following:

a) Review of research and non research literature used in the area related to side effect management of head and neck cancer.

b) Opinion and suggestions were taken from experts, which helped in determining the important areas to be included.

c) The investigators own exposure to clinical field helped in the development of the instrument.

Reliability of the tool was done by Split half method technique is usedCronbach Alpha Method. The reliability of the tool is 0.8075 which confirms that the tool was reliable.

To assess the level of knowledge of the patients undergoing head and neck radiation therapy the score was grouped into categories like poor, average and good based on the percentage of scores

\begin{tabular}{|l|l|l|}
\hline Sr. no & Level of knowledge & Score \\
\hline 1 & Poor & $0-8$ \\
\hline 2 & Average & $9-17$ \\
\hline 3 & Good & $18-26$ \\
\hline
\end{tabular}

\section{Data analysis}

Statistical package for social sciences (SPSS) 17.0 version for windows developed by IBM Corporation was used in data analysis in this study. The level of statistical significance for this study was set at $95 \%$ Independent sample t test, MannWhitney U test and Wilcoxon test were used to compare the means of pre test and post test knowledge scores.

\section{Ethics}

The study proposal was sanctioned by research ethics committee of related teaching and research institution. Permission was obtained from the 
concerned authority of the selected hospital for data collection. Informed consents were taken from the participants before participating in the study in order to maintain confidentiality and anonymity, participation and responses of the subjects were kept confidential. The subject had right to withdraw a consent at any time of the study.

\section{RESULTS}

\section{Patient characteristics}

Table 1: Description of samples according to demographic data of head and neck cancer patients receiving external radiation therapy.

\begin{tabular}{|c|c|c|c|}
\hline \multicolumn{2}{|l|}{ Parameters } & \multirow{2}{*}{$\begin{array}{l}\begin{array}{l}\text { No of } \\
\text { cases }\end{array} \\
4\end{array}$} & \multirow{2}{*}{$\begin{array}{l}\begin{array}{l}\text { Percentage } \\
(\mathbf{n}=\mathbf{3 5})\end{array} \\
11.4\end{array}$} \\
\hline Age (Yrs) & $21-40$ & & \\
\hline & $41-60$ & 29 & 82.9 \\
\hline & $61 \&$ above & 2 & 5.7 \\
\hline Gender & Male & 26 & 74.3 \\
\hline & Female & 9 & 25.7 \\
\hline Educational & Primary & 8 & 22.9 \\
\hline & Secondary & 10 & 28.6 \\
\hline & Graduate $\&$ above & 17 & 48.6 \\
\hline $\begin{array}{l}\text { Family } \\
\text { income (Rs) }\end{array}$ & $\begin{array}{l}11000-20000 \\
21000-30000 \\
31000 \& \text { above }\end{array}$ & $\begin{array}{l}7 \\
13 \\
15 \\
\end{array}$ & $\begin{array}{l}20 \\
37.1 \\
42.9\end{array}$ \\
\hline $\begin{array}{l}\text { Type of } \\
\text { treatment }\end{array}$ & $\begin{array}{l}\text { Radiation } \\
\text { Chemo and radiation } \\
\text { Surgery and radiation }\end{array}$ & $\begin{array}{l}15 \\
17 \\
3\end{array}$ & $\begin{array}{l}42.9 \\
48.6 \\
8.6\end{array}$ \\
\hline
\end{tabular}

Data given in [table 1] describe patient's characteristics. Thirty five subjects recruited in the study. The demographics of the subjects are listed in Table 1. Age: out of 35 patients, most of the patients $(82.9 \%)$ were seen in 41-60 The years, whereas $(11.4 \%)$ were in $21-40$ years of age group and $5.7 \%$ patients were in group of 61 years and above. Gender:- majority of the sample $(74.3 \%)$ were males and females were $25.7 \%$ Educational status:-48.6\% were found in the group of graduate and above, $28.6 \%$ were having secondary education and with primary education were $22.9 \%$. Previous Radiation:- majority were $97.1 \%$ with no previous history where as only $2.9 \%$ shown history of previous radiation. Family income:- Majority (42.9\%) were found with income Rs.31000 and above, $37.1 \%$ with Rs. 21000-30000 income and $20 \%$ with Rs.11000-20000 Type of treatment:- $48.6 \%$ shows patients receiving chemoradiation, $42.9 \%$ patients were seen receiving radiation only and with surgery and radiation were $8.6 \%$.

\section{Knowledge score of side effect management of patients undergoing} external radiation therapy in study group

[Table 2] shows that in pre test there was $51.1 \%$ patients had poor knowledge, $48.6 \%$ had average knowledge and no one had good knowledge whereas the post test scores are increased by $85.7 \%$ with good knowledge, $14.3 \%$ had average knowledge and no one had poor knowledge

Table 2: Knowledge score of side effect management of patients undergoing external radiation therapy in study group

\begin{tabular}{|l|l|l|}
\hline Knowledge score & Pre test & Post test \\
\hline $0-8$ (Poor) & $18(51.4)$ & 0 \\
\hline $9-17$ (Average) & $17(48.6)$ & $5(14.3)$ \\
\hline $18-26$ (Good) & 0 & $30(85.7)$ \\
\hline Total & $35(100)$ & $35(100)$ \\
\hline
\end{tabular}

Comparison of pre test score with post test score of side effect management of patients undergoing external radiation therapy.

[Table 3] shows that there is significant difference of knowledge score between pre and post test as $\mathrm{P}<0.0001$ i.e. knowledge score is significantly increase after administering information booklet. This means that tool is reliable.

Table 3: comparison of pre test score with post test score of side effect management of patients undergoing external radiation therapy.

\begin{tabular}{|l|l|l|l|l|l|l|}
\hline Parameter & Pre test & & Post test & & Wilcoxon $\mathrm{z}$ value & P Value \\
\cline { 1 - 5 } \cline { 7 - 8 } & Mean & SD & Mean & SD & & $<0.0001$ \\
\hline Knowledge score & 8.71 & 2.896 & 19.46 & 2.292 & 5.17 & \\
\hline
\end{tabular}

[Table 4.1] shows that there is no significant difference of pre test and post test knowledge score according to age as $\mathrm{p}>0.05$. 
Ujjwala Murkute et.al. A study to assess effect of information booklet on knowledge regarding side effect management in the patients of head and neck cancer undergoing external radiation therapy in selected hospital.

Table 4.1 Comparison of pre test score and post test score of side effect management of patients undergoing external radiation therapy in study group with demographic variables.

\begin{tabular}{|l|l|l|l|l|l|}
\hline Age (Yrs) & N & Pre test knowledge score & \multicolumn{2}{l|}{ Post test knowledge score } \\
\hline & & Mean & SD & Mean & SD \\
\hline $21-40$ & 4 & 9.25 & 2.630 & 20.50 & 2.380 \\
\hline $41-60$ & 29 & 8.90 & 2.895 & 19.45 & 2.308 \\
\hline $61 \&$ above & 2 & 5.00 & .000 & 17.50 & .707 \\
\hline F Value & & 1.86 & & 1.15 & \\
\hline P Value & & 0.17 & & 0.33 & \\
\hline
\end{tabular}

[Table 4.2] shows that there is no significant difference of pre test and post test knowledge score according to gender as $\mathrm{p}>0.05$

Table-4.2: Comparison of pre and post test knowledge score according to gender in study group.

\begin{tabular}{|l|lll|ll|l|}
\hline Knowledge score & \multicolumn{4}{|l|}{ Gender } & \multicolumn{3}{l|}{ MW test } & P Value \\
\hline & Male $(\mathbf{n}=\mathbf{2 6})$ & Female & $(\mathbf{n = 9})$ & U value & \\
\hline & Mean & SD & Mean & SD & & \\
\hline Pre test & 8.42 & 2.817 & 9.56 & 3.127 & 1.08 & 0.28 \\
\hline Post test & 19.31 & 2.328 & 19.89 & 2.261 & 0.54 & 0.59 \\
\hline
\end{tabular}

[Table 4.3] shows p-value there is no significant difference of pre test and post test knowledge score according to educational status as $\mathrm{p}>0.05$.

Table 4.3: Comparison of pre and post test knowledge score according to educational status in study group

\begin{tabular}{|l|l|l|l|l|l|}
\hline Educational status & N & Pre test knowledge score & \multicolumn{2}{l|}{ Post test knowledge score } \\
\hline & & Mean & SD & Mean & SD \\
\hline Primary & 8 & 8.50 & 3.423 & 18.88 & 2.416 \\
\hline Secondary & 10 & 7.70 & 2.214 & 19.10 & 1.663 \\
\hline Graduate \& above & 17 & 9.41 & 2.959 & 19.94 & 2.561 \\
\hline F Value & & 1.14 & & 0.75 & \\
\hline P Value & & 0.33 & & 0.48 & \\
\hline
\end{tabular}

[Table 4.4] shows that there is no significant difference of pre test and post test knowledge score according to family income as $\mathrm{p}>0.05$.

Table 4.4: Comparison of pre and post test knowledge score according to family income in study group

\begin{tabular}{|l|l|l|l|l|l|}
\hline Family income (Rs) & N & \multicolumn{2}{l|}{ Pre test knowledge score } & \multicolumn{2}{l|}{ Post test knowledge score } \\
\hline & & Mean & SD & Mean & SD \\
\hline $11000-20000$ & 7 & 8.71 & 3.147 & 18.86 & 1.345 \\
\hline $21000-30000$ & 13 & 9.46 & 3.178 & 19.46 & 2.367 \\
\hline $31000 \&$ above & 15 & 8.07 & 2.549 & 19.73 & 2.631 \\
\hline F Value & & 0.80 & & 0.33 & \\
\hline P Value & & 0.46 & & 0.72 \\
\hline
\end{tabular}

[Table 4.5] shows that there is no significant difference of pre test and post test knowledge score according to type of treatment as $p>0.05$.

Table 4.5: Comparison of pre and post test knowledge score according to type of treatment in study group

\begin{tabular}{|l|c|l|l|l|l|}
\hline Type of treatment & $\mathbf{N}$ & \multicolumn{2}{|l|}{ Pre test knowledge score } & \multicolumn{2}{l|}{ Post test knowledge score } \\
\hline & & Mean & SD & Mean & SD \\
\hline Radiation & 15 & 8.60 & 2.849 & 19.07 & 2.219 \\
\hline Chemo and radiation & 17 & 8.35 & 2.914 & 19.65 & 2.448 \\
\hline Surgery and radiation & 3 & 11.33 & 2.517 & 20.33 & 2.082 \\
\hline F value & & 1.40 & & 0.48 & \\
\hline P Value & & 0.26 & & 0.62 & \\
\hline
\end{tabular}

\section{DISCUSSION}

This study examined how an information booklet could affect the knowledge regarding side effect management of radiation therapy and weather there is any correlation between knowledge score and selected demographic variables.
Taneja C, et al (2002) in their study 'Changing patterns of failure of Head and Neck Cancer' states that The commonest age-group was 51-60 years comprising 44 patients $(40 \%) .16 \%$ cases were above 60 years of age, $29 \%$ were from the age group 41-50 years and $14 \%$ in $31-40$ years range. ${ }^{[12]}$ Similarly in the present study the results showed that most of the patients of 
head and neck cancer are males $(74.3 \%)$ as compared to females $(25.7 \%)$. The study also revealed that most of the patients $82.6 \%$ of head and neck patients were in the age group of $41-60$ years, and only $11.4 \%$ patients were in age group of 21-40 years.

In the study on 'Impact of providing booklets about chemotherapy to newly presenting patients with cancer: a randomized controlled trial' on Greek patients, G. IconomouA. et al (2006), stated that majority of patients $(68 / 71 ; 96 \%)$ would recommend the booklet to other patients with cancer. ${ }^{[13]}$ In the present study, there was a very positive feedback from the patients and they were motivated to read the booklet and also recommend the same to other patients. availability of basic information related to side effect and their management lead the further questioning and clarification from patients and they found to be satisfied by the information provided.

In a study conducted by Kaur Vijender, (2016) to assess the Effectiveness of Self Instructional Module for Improvement in Quality of Life of Breast Cancer Patients, with the sample size 150, showed that there was a significant difference between the mean of pre test and post test scores and there was a high level of acceptability of SIM by the breast Cancer patients. ${ }^{[14]}$ Similarly in present study also there was significant difference between pre test and post test knowledge score which proved that information booklet was very effective in enhancing knowledge of patient receiving radiation therapy.

In a study conducted by Ms. Ngawang Choenyi, et al (2016) on Knowledge Regarding Ill Effects of Chemotherapy and Its Home Management among Patients Receiving Chemotherapy', the result showed that there is no significant association was found between pretest knowledge scores with their demographic variables, like age, gender, education, area of living, and previous knowledge of chemotherapy. ${ }^{[15]}$ The present study also show there is no association knowledge score with demographic variables i.e age, gender, education, family income or type of treatment.

\section{Limitation}

There are certain limitations which are important to note before its implications in clinical nursing. this study had small sample size which may lead to errors in result. as there was not much control over contacts of subjects and information they might receive from other sources there are chances of some extraneous variables which might affect the findings of the study.

\section{Implications to nursing practice}

Nurse administrator should prepare adequate learning material for giving health education and making necessary educational material available to needy patients. The nurse administrator should emphasize the need for implementing planned educational strategies for improving the knowledge of the patient and care takers. As a nurse administrator, one should encourage a specific association of care takers who can then carry out periodic meetings and programmes so as to be of help for the new care takers.

Administrative authorities may recommend the use of information booklet as an education material in radiation department of hospital.

The oncology nurse should be able to use the information booklet to give health education to the patients and family members in the clinical area and supervise the symptomatic care measures adopted by the patients for the relief of the symptoms during radiation therapy.

This can also contribute in improving coping and help patient to manage them and get adjusted to new health challenges.

\section{CONCLUSION}

The information booklet on side effect management of radiation therapy had significantly favorable effect on knowledge of patient regarding side effect management. 
Awareness regarding the prevention and treatment measures at the beginning of therapy had positive impact on their behavior and coping as noted in follow up sessions which were continued after the data collection. Though there was no significant difference between knowledge score as per demographic variables, there was significant improvement in overall knowledge score. Many patient found the booklet very informative which became mean of further communication with nursing care personnel.

\section{Acknowledgement: None}

\section{Conflict of Interest: None}

\section{Source of Funding: None}

\section{Ethical Approval: Approved}

\section{REFERENCES}

1. Parkin DM, Bray F, Ferlay J, Pisani P. Estimating the world cancer burden: Globocan 2000. Int J Cancer. 2001; 94: 153156.

2. Michal SA, Adelstein DJ, Rybicki LA, et al. Multi-agent concurrent chemoradiotherapy for locally advanced head and neck squamous cell cancer in the elderly. Head Neck. 2012; 34: 1147-1152.

3. Brunner and Suddarth's. Textbook of medical surgical Nursing. Vol 1. Wolters Kluwer Publications. 2010; 349

4. Kearney Nora. Richard Alison. Nursing patients with cancer: Principles \& Practice. United Kingdom, Elsevier. 2006. 277.

5. Guleser GN, Tasci S, KalplanB. The experience of symptoms and informational needs of cancer patients undergoing radiotherapy. J Cancer Educa. March 2012; 27(1) 46-53.

6. Kearney Nora, Richard Alison. Nursing Patients with Cancer: Principles and practice. United Kingdom. Elsevier; 2006.277.

7. Rutten LJ, Arora NK, Bakos AD, Aziz N, Rowland J. Information needs and sources of the information among cancer patients: a systematic review of research. Patient Educ Couns. 2005 Jun; 57(3): 250-61.
8. Hagopian GA:The effects of informational audiotapes on knowledge and self carebehaviours of patients undergoing radiation therapy. Oncology Nursing Forum. 1996; 23(4): 697-700.

9. Skalla KA, Bakitas M, Furstenberg CT, Ahles T, Henderson JV. Patients' need for information about cancer therapy. Oncol Nurs Forum. 2004 Mar-Apr; 31(2): 313-9.

10. Jeff Dunn, Suzanne K. Steginga, Pauline Rose, Jenn Scott. Educating patient education materials about radiation therapy.Patient Education and Councelling.2004; 52: 325-332.

11. Alligood Martha Raile. Nursing theorists and their work. Eighth edition. United states. Elsevier publication 2014. 244-249

12. Taneja C, Allen H, Koness RJ, Radie-Keane $\mathrm{K}$ and Wancho HJ. Changing patterns of failure of Head and Neck Cancer. Arch Otolaryngol Head Neck Surg. 2002; 128: 324-327.

13. G. IconomouA. A. Viha A. Koutras I. Koukourikou V. Mega T. Makatsoris A. Onyenadumet al. Impact of providing booklets about chemotherapy to newly presenting patients with cancer: a randomized controlled trial Annals of Oncology. March 2006; 17(3): 515-520.

14. Kaur V. A study to assess the effectiveness of self instructional module for improvement in quality of life of breast cancer patients. Int J Health Sci Res. 2017; 7(2): 227-232.

15. Ms. Ngawang Choenyi, Kumari Mithelesh, Choedon Sonam, Kumari Meera,. Kumari Sachitra , Kumari Indu ,et al . Knowledge Regarding Ill Effects of Chemotherapy and Its Home Management among Patients Receiving Chemotherapy .OSR Journal of Nursing and Health Science (IOSR-JNHS). May- Jun. 2016; 5(3):25-29.

How to cite this article: Murkute U, Shaikh Nida Nausheen. A study to assess effect of information booklet on knowledge regarding side effect management in the patients of head and neck cancer undergoing external radiation therapy in selected hospital. Int J Health Sci Res. 2021; 11(7):281-289. DOI: https://doi.org/ 10.52403/ijhsr.20210738 